\title{
Aetna's Compassionate Care Program: Sustained Value for Our Members with Advanced Illness
}

\author{
Alena Baquet-Simpson, MD, ${ }^{1}$ Claire M. Spettell, PhD, ${ }^{1}$ Allison N. Freeman, MS, ${ }^{1}$ \\ Angelina M. Bates, APRN, A-GNP-C, ${ }^{1}$ Harold L. Paz, MD, MS, ${ }^{1}$ Robert Mirsky, MD, \\ Daniel B. Knecht, MD, MBA, and Troyen A. Brennan, MD, JD, MPH ${ }^{2}$
}

\begin{abstract}
Background: In 2004, Aetna, a national health insurer, launched the Aetna Compassionate Care Program (ACCP) targeting members diagnosed with an advanced illness with a view to increase access to palliative care and hospice services.

Objective: The objective of this study is to evaluate the impact of ACCP on health care utilization and hospice enrollment among enrolled members.

Methods: This was a retrospective cohort study comparing participants in ACCP to a matched control group using a propensity score method. The study group consisted of Aetna Medicare Advantage members who participated in the ACCP between January 2014 and June 2015. Potential control group members were those who were not identified by the predictive model nor were referred to the ACCP program through other means. The primary outcomes of interest were hospice use measured as percent of members electing hospice and median number of days in hospice; health care utilization and medical costs measured as rates and medical costs associated with acute inpatient admissions, emergency room, primary care, and specialty visits in the 30 and 90 days before death.

Results: Participants in the ACCP program were $36 \%$ more likely to enroll in hospice (79\% vs. 58\%, $p<0.0001$ ) and had reduced acute inpatient medical costs $(\$ 4169$ vs. $\$ 5863, p<0.0001)$ driven primarily by fewer inpatient admissions (860 vs. 1017, $p<0.0001$ ) in the last 90 days of life.

Conclusions: Advanced illness case management programs such as ACCP can improve access to hospice and improve patient outcomes while reducing unnecessary admissions in the last 90 days of life.
\end{abstract}

Keywords: care management; case management; hospice; Medicare Advantage; utilization

\section{Introduction}

$\mathbf{T}$ HE GOAL of the Triple Aim is to improve population health, reduce per-capita costs, and improve patient experiences. This has created a paradigm shift in the health care landscape, with increasing emphasis on interventions that improve quality of care and patient outcomes while reducing health care cost/utilization. These opportunities are especially relevant in the realm of end-of-life care. Studies show that patients and family members with advanced illnesses often have very poor satisfaction with the end-of-life care they receive. ${ }^{1}$ This is, in part, due to a discord between the type of care they prefer and that which they actually receive. Despite the fact that the majority of Americans prefer to die at home without aggressive medical interventions, ${ }^{2}$ a large portion of deaths continue to occur in hospitals and nursing homes. ${ }^{3,4}$ Furthermore, most patients at the end of their life have higher health care utilization, with increased emergency department visits and medical/intensive care unit (ICU) admissions, and multiple transitions in care. ${ }^{3,4}$ There is a substantial body of literature demonstrating the value that palliative care and hospice programs bring to end-of-life care. ${ }^{5-10}$ Studies show that patients who enroll in hospice or palliative care earlier tend to have higher perceived quality of life and patient satisfaction. ${ }^{5-10}$

Despite documented benefits, both palliative care and hospice services remain underutilized. ${ }^{11}$ In 2015, 1.3 million

\footnotetext{
${ }^{1}$ Aetna, a CVS Health Company, Hartford, Connecticut.

${ }^{2}$ CVS Health, Woonsocket, Rhode Island.

Accepted March 28, 2019.
} 
individuals were enrolled in hospice; with the median length of service of 23 days, ${ }^{12}$ which is only slightly higher than 2006 (20.6 days). ${ }^{13}$ Approximately one-quarter of hospice decedents enroll in hospice in the last week of life ${ }^{12,14}$; significantly limiting the benefit they might obtain from enrolling in palliative care or hospice services. ${ }^{15,16}$ A large portion of these patients live at home thus putting a significant emotional and financial strain on caregivers. ${ }^{17}$ Researchers have cited the following barriers to hospice enrollment: cultural or religious beliefs, socioeconomic factors, disparities in access to care, ${ }^{11}$ lack of public awareness, ${ }^{18,19}$ restrictions imposed by Medicare Hospice Benefit, ${ }^{20}$ and lack of physician training/ comfort to engage in such discussions. ${ }^{11}$

Since 2004, Aetna, a national health insurance provider, has offered an end-of-life comprehensive case management program termed the "Aetna Compassionate Care Program" (ACCP). ${ }^{13}$ The program offers advanced illness nurse-led telephonic case management services to members and their families who are managing the complex and emotional issues involved with end-stage and/or life-limiting illnesses. ${ }^{13}$ This specialized case management program supplements the traditional case management services available to all health plan members.

The program uses a multifaceted approach of predictive modeling and referrals from various sources to identify members for ACCP. A proprietary predictive model mines medical and pharmacy claims on a monthly basis to identify individuals whose claims history suggests a terminal illness. The model features include combinations of diagnosis categories for 20 leading causes of death (e.g., specific cancers, chronic renal failure, AIDS, chronic obstructive pulmonary disease, and respiratory failure), use of pain medications, noncompliance with certain types of drugs, procedures for treating pain, chemotherapy, specific types of pharmacy claims, age, gender, and consumer buying patterns. Aetna's predictive model had a positive predictive value of 0.6259 at the model cutoff point of 0.55 , which is the threshold used for the ACCP program.

Members qualify for outreach if they have a likelihood of death in the upcoming 12 months of $55 \%$ or greater. Members can qualify and be referred into the program if diagnosed with an advanced illness with irreversible decline and/or are medically fragile with high risk for hospital admission, cost or need for additional services. Case managers may identify members for the ACCP program regardless of their predictive model score. In addition, members are identified through the health plan's daily review of inpatient admissions, as well as physician referrals and self-referrals. Registered nurse case managers, trained in managing advanced illness and motivational interviewing, engage members and provide individualized care plans to guide, support, and educate members based on their end-of-life preferences and in collaboration with their health care providers as needed.

Case manager training for ACCP includes a robust curriculum addressing motivational interviewing, understanding advanced illness and related symptoms, hospice care, the Karnofsky Performance Scale, advance directives, having difficult conversations, and cultural considerations. In addition, case managers are required to complete end of liferelated continuing education units annually. Case managers are also supported with ongoing mentoring and lunch and learn sessions on various topics. Certification is not required.
About 250-300 members per month are invited to participate in the program during this time period, with $70 \%$ agreeing to participate. On average, members engaged in Aetna Compassionate Care have 15.7 clinical contacts from a combination of case managers, pharmacists, and social workers. These contacts include activities such as assessments, medication reconciliation, education, assistance with advance directives, assisting in accessing community resources, and other support activities. The average length of time members are engaged in the program is 6.4 months.

In 2009, this program was evaluated in a retrospective study comparing members who received specialized advanced illness nurse-led telephonic case management services with matched historical controls received the usual case management services. ${ }^{13}$ The study showed increased hospice utilization and longer length of time spent in hospice for all members compared to controls. In addition, participants in the program had a reduction in inpatient stays compared with controls. The aim of this report is to examine whether the ACCP, now approximately a decade since its inception, continues to show sustained improvements in patient outcomes and health care costs.

This study was designed to evaluate the impact of the program on utilization of health care services in the last three months of life, including hospitalizations, outpatient visits, emergency department visits, and other services, including hospice use. Hospice use was expected to be higher among ACCP participants compared with the control group. Acute hospitalizations and costs were expected to be lower among program participants compared with the control group.

\section{Methods \\ Study design and population}

Aetna Medicare Advantage members with medical and pharmacy benefits who had died between January 2014 and June 2016 were identified from the Centers for Medicare and Medicaid Services' Daily Transaction Reply Report (TRR). ${ }^{21}$ From this list of members, the ACCP participant group consisted of those members who had been identified for and participated in the ACCP program between January 2014 and June 2015. Potential control group members were those who were not identified nor were referred to the ACCP program before dying. Fifty-six percent of members in the study were identified via the predictive algorithm, with the remaining $44 \%$ identified through referral from other case management programs. Individuals living in skilled nursing facilities or long-term care were excluded from the analysis as they would not be managed by the program.

This retrospective cohort study compared participants in Aetna's ACCP program to a matched control group of individuals. Program participants and potential control group members were matched using a propensity score method developed by researchers at the Mayo Clinic Division of Biostatistics. ${ }^{22}$ Participants and control group members were matched one-to-one using a propensity score created with logistic regression and the Greedy Nearest Neighbor matching algorithm. The propensity score model predicted the likelihood of being a participant in the ACCP program, and included demographics (gender, age, and state of residence), diagnosis category and risk scores (International Classification of Diseases [ICD] chapter, ${ }^{23}$ Episode Risk 
Group retrospective risk score, ${ }^{24}$ Charlson Comorbidity Index score ${ }^{25}$ ), baseline health care utilization measures (acute inpatient admission rate, emergency department visit rate), total medical costs, and number of months of Aetna medical eligibility before death. Data for the analysis came from the health plan's eligibility, medical claims, and utilization management systems.

The study period was defined as the three months before date of death. This time period was selected because health care utilization spikes dramatically in these months before death. The baseline period, used for matching intervention to control members, was defined as 4 months prior and up to 12 months before the date of death, and study participants were required to have been enrolled with Aetna and participating in the ACCP program for at least 4 months before death.

\section{Outcome measures}

Hospice use. Percent of members electing hospice and median number of days in hospice were calculated through the health plan case management database and Centers for Medicare and Medicaid Services' Daily TRR, which identified members for whom hospice claims were paid directly by CMS.

Health care utilization. Measures included the rate of acute inpatient admissions, as well as the rates of emergency room, primary care, and specialist physician visits in the 30 and 90 days before death, and expressed as rate per 1000 members.

Medical costs. Medical cost measures were calculated from health plan claims data and included total medical allowable expenditures, as well as costs for acute inpatient admissions, emergency room visits, primary care, and specialist physician outpatient visits. Medical claims related to hospitalizations resulting from trauma or unexpected illnesses were excluded from these calculations (Table 1). Pharmacy costs were measured from claims paid under the pharmacy benefit. All cost measures were calculated on a per

Table 1. International Classification of Diseases Chapters (Diagnosis Groups) Excluded From Admissions Outcome Metric

\begin{tabular}{l} 
Diagnosis groups \\
Anaphylactic shock \\
Endocarditis/pericarditis/myocarditis \\
Burns \\
Drug adverse effect \\
Poisoning \\
Encephalitis/meningitis \\
Head injury \\
Fractures \\
Sprains/strains \\
Appendicitis \\
Accidental injury/assault \\
Major trauma/organ system injury \\
Abdominal aortic aneurysm \\
Arterial thrombosis/embolism \\
Contusion/crushing injury \\
Spinal cord injury \\
Concussion \\
\hline
\end{tabular}

member per month (PMPM) basis for the periods of 30 and 90 days before death.

\section{Statistical analyses}

Paired $t$ tests were conducted to compare averages of medical cost variables, and McNemar's chi-square tests were used to compare binary variables. Pearson chi-square tests were used to compare multilevel variables, condition and state, by cohort. The Wilcoxon Rank Sum test was used to compare median duration in hospice. For utilization (count) variables, generalized linear models with Poisson or Negative Binomial distribution were used to assess differences between the cohorts. To mitigate influence of outliers, costs and utilization were capped at 99.7th and 99.8th percentile, respectively. A significance level of $\alpha<0.05$ was used for all statistical tests. All analyses were performed using the SAS v $9.4^{\odot}$.

\section{Results}

\section{Baseline descriptive statistics}

To examine balance between matched groups, groups were compared on the features used in the propensity score plus additional categories of medical cost, outpatient physician visits, and condition prevalence (Table 2). The groups were well matched on nearly all characteristics, including age, gender, risk, and conditions before death, and prior utilization and medical costs. At nearly one-third per group, neoplasms were the most prevalent condition in both groups. Both groups were geographically dispersed with greater concentrations in certain states (TX, PA, NJ, and FL).

\section{Health care utilization and costs}

Figure 1 shows the rates of inpatient admissions for the two groups in the 12 months before death. The groups showed a similar pattern of gradually increasing rates of admission, which then increased sharply in the three months before death. The median time for ACCP engagement was four months before death.

Table 3 shows cost and utilization measures for study and control members in the last 90 days and the last 30 days of life. In the last 90 days of life, ACCP participants had $15 \%$ fewer inpatient admissions than the control group (860 per 1000 members vs. 1017 per 1000 members, $p<0.0001$ ). Rates of emergency department visits, primary care physician, and specialist physician visits did not differ between the two groups. Acute inpatient medical costs were $\$ 1664$ PMPM lower for ACCP participants compared to controls (\$4169 vs. $\$ 5833$ PMPM, $p=0.0159$ ). Total medical costs showed a trend for lower costs (\$12,756 vs. \$14,609 PMPM, $p=0.06$ ). Other cost categories were not significantly different between the two groups.

A similar pattern of results was seen in the last 30 days of life for inpatient admissions, emergency department visits, inpatient costs, and pharmacy costs. Within the 30 days before death, total medical expenditures for participants in the program were $\$ 3059$ lower on average compared with the matched control group $(\$ 16,653$ vs. $\$ 19,712, p<0.0001)$. Again, this was driven by differences in acute inpatient admissions and related expenditures; participants in the program had 133 fewer acute inpatient admissions per thousand individuals compared with the control group (415 vs. 548, 
Table 2. Baseline Characteristics of Aetna Compassionate Care Program Participants AND CONTROL GROUPS

\begin{tabular}{|c|c|c|c|c|c|}
\hline \multirow[b]{2}{*}{ Characteristic } & \multicolumn{2}{|c|}{ ACCP participants } & \multicolumn{2}{|c|}{ Nonparticipants } & \multirow[b]{2}{*}{$\mathrm{p}$} \\
\hline & $\% /$ Mean & $S D$ & $\% /$ Mean & $S D$ & \\
\hline$N$ & 299 & & 299 & & \\
\hline Age & 81.70 & 7.89 & 81.88 & 8.41 & 0.7815 \\
\hline$\%$ Male & $60 \%$ & & $56 \%$ & & 0.3707 \\
\hline Retrospective Episode Risk Group & 17.41 & 9.04 & 17.05 & 11.33 & 0.6008 \\
\hline Charlson Comorbidity Score & 4.01 & 3.07 & 4 & 2.92 & 0.9523 \\
\hline Conditions & & & & & 0.9216 \\
\hline Neoplasms & $27 \%$ & & $31 \%$ & & \\
\hline Circulatory & $17 \%$ & & $16 \%$ & & \\
\hline Respiratory & $9 \%$ & & $7 \%$ & & \\
\hline Infections & $11 \%$ & & $10 \%$ & & \\
\hline Injury and poisoning & $5 \%$ & & $5 \%$ & & \\
\hline State & & & & & 0.2339 \\
\hline TX & $13 \%$ & & $14 \%$ & & \\
\hline $\mathrm{PA}$ & $10 \%$ & & $10 \%$ & & \\
\hline NJ & $10 \%$ & & $10 \%$ & & \\
\hline FL & $10 \%$ & & $8 \%$ & & \\
\hline $\mathrm{OH}$ & $4 \%$ & & $9 \%$ & & \\
\hline All other & $53 \%$ & & $49 \%$ & & \\
\hline \multicolumn{6}{|c|}{ Prior utilization (mean per 1000 members per year) } \\
\hline Acute admissions & 967 & 1279 & 977 & 1330 & 0.9240 \\
\hline Emergency department visits & 659 & 1175 & 642 & 1079 & 0.8464 \\
\hline Primary care physician visits & 4465 & 4974 & 4234 & 4555 & 0.5565 \\
\hline Specialist visits & 8214 & 8623 & 7117 & 7771 & 0.0693 \\
\hline \multicolumn{6}{|l|}{ Costs (mean per member per month) } \\
\hline Total medical cost & $\$ 6356$ & $\$ 7035$ & $\$ 6257$ & $\$ 9340$ & 0.8768 \\
\hline Pharmacy cost & $\$ 607$ & $\$ 1359$ & $\$ 609$ & $\$ 1413$ & 0.9793 \\
\hline
\end{tabular}

The engaged and control groups were well matched on demographic characteristics, comorbid conditions, prior utilization, and costs. Differences between the groups were insignificant for most variables.

ACCP, Aetna Compassionate Care Program; SD, standard deviation.

$p=<0.0001)$. Also notable is a significant increase in specialist and primary care physician cost for ACCP program participants during the 30-day period before death.

\section{Hospice use}

As shown in Table 3, participants in the ACCP program were enrolled in hospice at a greater rate than those in the control group $(79 \%$ vs. $58 \%, p<0.0001)$. Those who par-

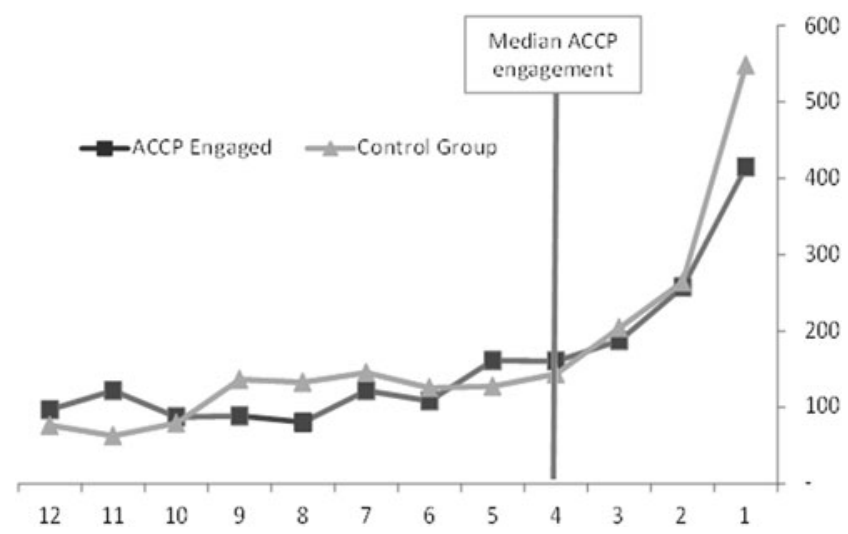

FIG. 1. Acute inpatient admissions per thousand in the last 12 months of life by group. ticipated in the program showed a trend for longer duration of hospice use compared with those in the control group (26 vs. 19 days, $p=0.0620)$.

\section{Discussion}

In summary, insured members in this study who received ACCP services were $36 \%$ more likely to enroll in hospice and had reduced health care costs primarily driven by fewer inpatient admissions compared to members who received usual case management services alone. These findings are consistent with the findings of the previous study published in $2009^{13}$ as well as studies that looked at outpatient palliative care. ${ }^{6,8,26-29}$ While the results of the present study are consistent with those of the earlier study of the ACCP, there were some notable differences. In the prior study, members with terminal cancer diagnoses represented $57 \%$ of the Medicare sample; in the current study, cancer diagnoses represented $27 \%$. Length of time between enrollment in the program and death increased from 56.7 days in the first study to 4 months (median) in the current study.

While discussing end-of-life care models, it is important to distinguish between hospice and palliative care. Palliative care can begin at diagnosis, and at the same time as treatment; whereas hospice care begins when curative treatment has stopped and patient has been certified by a physician to have 
Table 3. Summary of Study Outcomes

\begin{tabular}{|c|c|c|c|}
\hline Measure & ACCP participants & ACCP nonparticipants & $\mathrm{p}$ \\
\hline \multicolumn{4}{|l|}{ Hospice use } \\
\hline Percent electing hospice & $79 \%$ & $58 \%$ & $<0.0001$ \\
\hline Median days in hospice & 26 & 19 & 0.0620 \\
\hline 90 Days before death & ACCP participants & Control group & $\mathrm{p}$ \\
\hline \multicolumn{4}{|c|}{ Utilization metrics (mean per thousand members per year) } \\
\hline Acute inpatient admissions & 860 & 1017 & $<0.0001$ \\
\hline Emergency department visits & 338 & 395 & 0.7362 \\
\hline Primary care physician visits & 1314 & 1384 & 0.8533 \\
\hline Specialist visits & 1993 & 1652 & 0.5144 \\
\hline \multicolumn{4}{|c|}{ Cost metrics (mean per member per month) } \\
\hline Total medical cost & $\$ 12,756$ & $\$ 14,609$ & 0.0601 \\
\hline Acute inpatient cost & $\$ 4169$ & $\$ 5833$ & 0.0159 \\
\hline Emergency department cost & $\$ 141$ & $\$ 199$ & 0.1246 \\
\hline Primary care physician cost & $\$ 31$ & $\$ 42$ & 0.1907 \\
\hline Specialist physician cost & $\$ 79$ & $\$ 55$ & 0.1017 \\
\hline Pharmacy cost & $\$ 569$ & $\$ 604$ & 0.8007 \\
\hline 30 Days before death & ACCP participants & Control group & $\mathrm{p}$ \\
\hline \multicolumn{4}{|c|}{ Utilization metrics (mean per thousand members per year) } \\
\hline Acute inpatient admissions & 415 & 548 & $<0.0001$ \\
\hline Emergency department visits & 127 & 177 & 0.6732 \\
\hline Primary care physician visits & 441 & 451 & 0.9601 \\
\hline Specialist visits & 679 & 595 & 0.7149 \\
\hline \multicolumn{4}{|c|}{ Cost metrics (mean per member per month) } \\
\hline Total medical cost & $\$ 16,653$ & $\$ 19,712$ & $<0.0001$ \\
\hline Acute inpatient cost & $\$ 5716$ & $\$ 8333$ & 0.0276 \\
\hline Emergency department cost & $\$ 123$ & $\$ 230$ & 0.1065 \\
\hline Primary care physician cost ${ }^{\mathrm{a}}$ & $\$ 108$ & $\$ 45$ & 0.0003 \\
\hline Specialist physician cost & $\$ 219$ & $\$ 66$ & $<0.0001$ \\
\hline Pharmacy cost & $\$ 460$ & $\$ 475$ & 0.9168 \\
\hline
\end{tabular}

Members engaged in ACCP were 36\% more likely to use hospice than control group, and hospice duration was $37 \%$ longer when engaged in ACCP. Study period costs and utilization are lower in the ACCP engaged group compared with those not engaged.

a life expectancy less than six months (based on current Medicare rules). ${ }^{30}$ Over the past decade, there has been a shift in the epidemiology of death and end-of-life care with more people dying from noncancer diagnoses such as Dementia and advanced chronic respiratory failure, which tend to have a less predictable course and a life expectancy longer than six months. ${ }^{3}$ Hence, patients with these diagnoses often do not meet the criteria for Medicare hospice and receive it later in their course, or if enrolled in hospice are more likely to experience disenrollment, which can negatively impact quality of life and health care utilization. ${ }^{3}$ While we must push for changes in policy to address the Medicare Hospice benefit, in the interim outpatient palliative care programs and case management programs such as the ACCP can improve outcomes in such patients. ${ }^{20}$

Lack of public awareness has been cited as a barrier to palliative care utilization. ${ }^{18,19}$ For instance, many patients do not realize that they can be enrolled in palliative care without being enrolled in hospice or start off in palliative care and transition to hospice care at a later date. The ACCP can help members with that transition, which may reduce barriers to hospice utilization as well. Under ACCP, the case managers help members and their families think about what their wishes really are and encourage members and families to make choices appropriate for them. In addition, improved communication with patients helps improve their awareness of disease prognosis and course. ${ }^{31}$ When members understand their prognosis and options, they tend to choose less traditional care, thereby leading to increased and earlier enrollment in hospice.

From an economic standpoint, this study shows that concerted advanced illness nurse-led telephonic case management efforts also lead to a reduction in health care utilization and costs in the last three months of life. This is especially relevant in the context of an aging population living longer with advanced chronic illnesses. Forty percent of the costliest $5 \%$ of patients tend to be elderly, have multiple chronic illnesses, tend to have significant functional limitations, are often nursing home residents, tend to report low quality of life and patient satisfaction and cannot avail of hospice due to the six months restriction imposed by Medicare. ${ }^{11,32}$ Outpatient multidisciplinary palliative care programs and supportive case management programs can help improve outcomes while reducing costs in this population.

This study has several limitations. This was not a randomized control trial; hence, differences between study and control groups could be related to unmeasured baseline differences between the two groups. Controls were members who were 
neither outreached to nor engaged as they were not identified by the predictive model or referred by care providers. About $30 \%$ of members who were outreached to did not engage in the program. These differences could introduce a bias that might have influenced the differences in outcomes between both groups. The study was limited to Aetna members alone and as such may not be generalizable to patients enrolled in other health plans. The study did not measure perceived quality of care and patient satisfaction scores between the two groups.

The results of this study are consistent with the prior study of ACCP, and also consistent with studies of palliative care programs delivered in a variety of settings. ${ }^{13,27}$ The strength of the ACCP lies in the fact that case managers working with patients receive specialized training in managing advanced illness. In addition, case managers continue to work with and support members who choose hospice for 90 days posthospice election to facilitate a smooth transition and avoid any perceptions of abandonment. This long follow-up has been vital in helping case managers establish meaningful relationships with patients and family members. Ongoing mentoring and training has been crucial in developing the skills required to have such difficult conversations. It should further be emphasized that Aetna does not have a special palliative care benefit above that offered through Medicare. The case managers under ACCP help members access the care available to them as part of their standard benefits. We believe that these are the key drivers behind the success of the program and hope that this program can serve as a model for other managed care programs planning similar end-of-life care interventions. Given the success of the program, it is conceivable that other patients with chronic and advanced illness would benefit from such end-of-life care earlier than the last three months of their life.

\section{Acknowledgment}

The authors wish to thank Margaret Mayorga, MPH, MS for data manipulation and statistical analyses.

\section{Author Disclosure Statement}

All authors of this publication are currently or previously employed by CVS Health or Aetna, a CVS Health Company, and may own equity in the company. No further potential conflicts of interest have been identified.

\section{References}

1. Teno JM, Clarridge BR, Casey V, et al.: Family perspectives on end-of-life care at the last place of care. JAMA 2004;291:88-93.

2. Fischer S, Min SJ, Cervantes L, Kutner J: Where do you want to spend your last days of life? Low concordance between preferred and actual site of death among hospitalized adults. J Hosp Med 2013;8:178-183.

3. Aldridge MD, Bradley EH: Epidemiology and patterns of care at the end of life: Rising complexity, shifts in care patterns and sites of death. Health Aff (Millwood) 2017;36:1175-1183.

4. Meghani SH, Hinds PS: Policy brief: The Institute of Medicine report Dying in America: Improving quality and honoring individual preferences near the end of life. Nurs Outlook 2015;63:51-59.
5. Kavalieratos D, Corbelli J, Zhang D, et al.: Association between palliative care and patient and caregiver outcomes: A systematic review and meta-analysis. JAMA 2016;316: 2104-2114.

6. Lustbader D, Mudra M, Romano C, et al.: The impact of a home-based palliative care program in an accountable care organization. J Palliat Med 2017;20:23-28.

7. Bakitas M, Lyons KD, Hegel MT, et al.: Effects of a palliative care intervention on clinical outcomes in patients with advanced cancer: The Project ENABLE II randomized controlled trial. JAMA 2009;302:741-749.

8. Rabow M, Kvale E, Barbour L, et al.: Moving upstream: A review of the evidence of the impact of outpatient palliative care. J Palliat Med 2013;16:1540-1549.

9. Brumley R, Enguidanos S, Jamison P, et al.: Increased satisfaction with care and lower costs: Results of a randomized trial of in-home palliative care. J Am Geriatr Soc 2007;55: 993-1000.

10. Temel JS, Greer JA, Muzikansky A, et al.: Early palliative care for patients with metastatic non-small-cell lung cancer. N Engl J Med 2010;363:733-742.

11. Meier DE, Back AL, Berman A, et al.: A national strategy for palliative care. Health Aff (Millwood) 2017;36:12651273.

12. National Hospice and Palliative Care Organization: NHPCO Facts and Figures: Hospice Care in America, 2016 edition. www.nhpco.org/sites/default/files/public/Statistics_Research /2016_Facts_Figures.pdf (last accessed May 31, 2019).

13. Spettell CM, Rawlins WS, Krakauer R, et al.: A comprehensive case management program to improve palliative care. J Palliat Med 2009;12:827-832.

14. Teno JM, Gozalo PL, Bynum JP, et al.: Change in end-oflife care for Medicare beneficiaries: Site of death, place of care, and health care transitions in 2000, 2005, and 2009. JAMA 2013;309:470-477.

15. National Quality Forum: National Voluntary Consensus Standards for Quality of Cancer Care: A Consensus Report. Washington, DC: The Forum, 2009. www.qualityforum.org/ Publications/2009/05/National_Voluntary_Consensus_ Standards_for_Quality_of_Cancer_Care.aspx (last accessed May 31, 2019).

16. Taylor DH, Jr., Ostermann J, Van Houtven CH, et al.: What length of hospice use maximizes reduction in medical expenditures near death in the US Medicare program? Soc Sci Med 2007;65:1466-1478.

17. Ornstein KA, Kelley AS, Bollens-Lund E, Wolff JL: A national profile of end-of-life caregiving in the United States. Health Aff (Millwood) 2017;36:1184-1192.

18. Center to Advance Palliative Care: 2011 Public Opinion Research on Palliative Care: A Report Based on Research by Public Opinion Strategies. New York, NY: CAPC. https:// media.capc.org/filer_public/3c/96/3c96a114-0c15-42da-a07f11893cca7bf7/2011-public-opinion-research-on-palliativecare_237.pdf (Last accessed May 17, 2017).

19. Shalev A, Phongtankuel V, Kozlov E, et al.: Awareness and misperceptions of hospice and palliative care: A populationbased survey study. Am J Hosp Palliat Care 2018;35:431-439.

20. Kelley AS, Morrison RS: Palliative care for the seriously ill. N Engl J Med 2015;373:747-755.

21. Centers for Medicare and Medicaid Services' Daily Transaction Reply Report (TRR): www.cms.gov/ResearchStatistics-Data-and-Systems/CMS-Information-Technology/ 
mapdhelpdesk/Downloads/PCUG-Appendices-v110-February28-2017.pdf (last accessed May 31, 2019).

22. Bergstralh EJ, Kosanke JL: Computerized Matching of Cases to Controls. 1995; Technical Report 56. www.mayo.edu/ research/departments-divisions/department-health-sciencesresearch/documents/biostat-56pdf/doc-10026923 (last accessed May 31, 2019).

23. ICD Codes: https://icd.codes/icd10cm (last accessed May 31, 2019).

24. Episode Risk Group: www.optum.com/content/dam/optum3/ optum/en/resources/white-papers/Symmetry_ERG_White_ Paper_July181.pdf (last accessed May 31, 2019).

25. Charlson ME, Pompei P, Ales KL, MacKenzie CR: A new method of classifying prognostic comorbidity in longitudinal studies: Development and validation. J Chronic Dis 1987;40:373-383.

26. Brian Cassel J, Kerr KM, McClish DK, et al.: Effect of a home-based palliative care program on healthcare use and costs. J Am Geriatr Soc 2016;64:2288-2295.

27. Smith S, Brick A, O'Hara S, Normand C: Evidence on the cost and cost-effectiveness of palliative care: A literature review. Palliat Med 2014;28:130-150.

28. Kerr CW, Donohue KA, Tangeman JC, et al.: Cost savings and enhanced hospice enrollment with a home-based pal- liative care program implemented as a hospice-private payer partnership. J Palliat Med 2014;17:1328-1335.

29. Gomes B, Calanzani N, Curiale V, et al.: Effectiveness and cost-effectiveness of home palliative care services for adults with advanced illness and their caregivers. Cochrane Database Syst Rev 2013;6:CD007760.

30. U.S. Centers for Medicare \& Medicaid Services: Hospice \& respite care. www.medicare.gov/coverage/hospice-care (last accessed May 31, 2019).

31. Aiken LS, Butner J, Lockhart CA, et al.: Outcome evaluation of a randomized trial of the PhoenixCare intervention: Program of case management and coordinated care for the seriously chronically ill. J Palliat Med 2006;9:111-126.

32. Schoenman JA: The Concentration of Health Care Spending. Washington, DC: National Institute for Health Care Management Research and Educational Foundation, 2012.

Address correspondence to:

Alena Baquet-Simpson, $M D$

Aetna

clo Charita Henry

101 Park Avenue, 15th Floor New York, NY 10178

E-mail: axsimpson@aetna.com 